ISASE 2020

\title{
Luxury Fashion in Online Platform Service
}

\author{
Chikako MIURA*, Sakiho KAI**, Takao FURUKAWA** and Kaoru MORI*** \\ * Formerly of Kyoritsu Women's University, 2-2-1 Hitotsubashi, Chiyoda-ku, Tokyo 101-8437, Japan \\ 07d148cs@og.kyoritsu-wu.ac.jp \\ ** Kyoritsu Women's University, 2-2-1 Hitotsubashi, Chiyoda-ku, Tokyo 101-8437, Japan \\ \{sakihokai,tfurukawa\}@kyoritsu-wu.ac.jp \\ *** Keio University, 5322 Endo, Fujisawa-shi, Kanagawa 252-0882, Japan \\ kmori@sfc.keio.ac.jp
}

\begin{abstract}
High quality but low price is a fundamental factor for commodities, however, tangible and intangible added value is the most important factor for luxury products. To pursue added value of luxury fashion brands and products, this paper shed light online platform service dealing with a large amount of products, and aims to reveal the actual situation of the luxury fashion market. The importance of online platform service as a data source is discussed in terms of network externality required for modern services. This paper proposes sales amount analysis and analyzed 308,154 luxury fashion items. The results show availability of category extension in luxury brands to raise the sales. Integrity of high sales amount products is also discussed on brand equity fascinating consumers.

Keywords: Luxury fashion, Online platform service, Sales amount, Category extension, Brand equity
\end{abstract}

\section{INTRODUCTION}

Fashion is an important industry driving global economics in the context of world-wide population growth and economic development in developing and emerging countries. In 2016, the global market size of the fashion industry was estimated to be \$US 2.4 trillion with $5.5 \%$ CAGR [1]. The fashion product market has often been modeled as a pyramidal structure comprised of several layers [2]. In the pyramidal model, the top layer corresponds to luxury fashion market in which high quality and premium price characterize the products. Meanwhile, the bottom layer corresponds to mass-volume market in which the low-priced products distribute. The remaining middle layer corresponds to intermediate market.

The luxury fashion market has been expanding in accordance with economic growth in emerging countries, in particular China with huge market potential. Luxury fashion brands propose cutting-edge fashion trends at their fashion shows held in New York, London, Milan, and Paris every season. In the trickle-down theory of fashion trend diffusion [3], those fashion trends propagate downward in the pyramid, which give significant impacts to the whole fashion market.

Luxury brands and the products have been addressed as interdisciplinary studies from multi-facet aspects - brand management [e.g. 2], retail and distribution management [e.g. 4], and consumer psychology [e.g. 5]. These studies were classified into the producer-side or the consumerside analyses. Consumer psychology and behavior of luxury fashion products [5] is a typical consumer-side analysis. Studies on brand management focusing on brand equity [6] are also classified into the consumer-side analysis. On the other hand, producer-side analyses have been limited to several case studies targeting specific brands [4]. Although high quality but low price is a fundamental factor for commodities, tangible and intangible added value is the most important factor for luxury products, which is a major topic in affective engineering. This paper sheds light on luxury fashion brand and aims to reveal the actual situation of the luxury fashion market focusing on brand extension [7].

\section{DISTRIBUTION CHANNELS OF LUXURY FASHION PRODUCTS}

\subsection{Classification of distribution channels}

Figure 1 classifies distribution channels of luxury fashion products, which is closely related to exclusivity, rarity, and extraordinary experiences [8]. The primary distribution deals unused, brand-new or new old stock products. The secondary distribution deals second hand products already used by consumers. The diagram subdivides the primary distribution into directly managed stores, distributors, and online stores. The directly managed stores are comprised of flagship stores, regular price retail stores, department store concessions, and 
designer outlet factory stores. In this figure, range of sold products determines the vertical position of each distribution channel. The top flagship stores cover all products of the brand; meanwhile, designer outlet factory stores deal the limited number of discounted products.
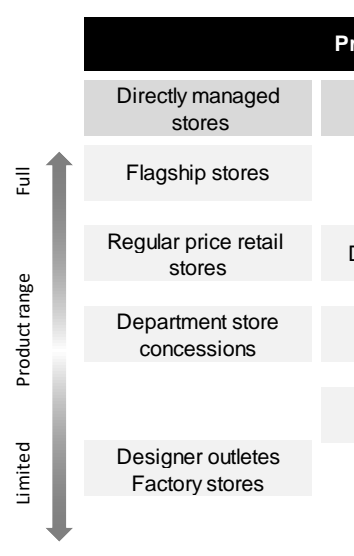

Primary distribution

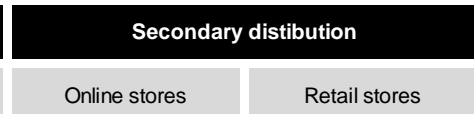

Distributors are comprised of department stores, specialty stores and duty-free shops in airports.

Figure 1: Distribution channels of luxury products.

Online stores are comprised of official online stores, multi-brand online stores often called E-tailers, online platform services, and online auction services for new old stock products. Multi-brand online stores, e.g. Net-APorter and Yoox, deal with various luxury fashion brands and products. Online platform service is represented by Farfetch aggregating online retailers also deal with various luxury fashion brands and products. New old stocks of luxury fashion products have often been sold online auction services like eBay.

The secondary distribution is comprised of $\mathrm{C} 2 \mathrm{C}$ online auction and online consignment service in online stores and vintage stores of conventional retailer. Online consignment service like RealReal receives and sells second hand luxury fashion products in their online store, which attract attention related to environmental effect reducing $\mathrm{CO} 2$ emissions and water consumption.

\subsection{Online platform service}

In 2008, José Neves established Farfetch operating online platform service in London, focusing on luxury fashion. In 2019, Farfetch acquired 1.7 million active users and achieved \$US 1.5 billion Gross Merchandise Volume (GMV) which is 5.3 times larger than the GMV in 2015. The CAGR of GMV from 2015 to 2018 showed $55 \%$ increase [7].

In the online platform service, Farfetch provides a marketplace for multiple retailers. The distinctive feature of Farfetch's online platform service is an external dependency of stock management, even they manage order processing and distribution tasks. This business model isolates non-scalable function limited by physical condition and focuses on scalable function enhanced by information technology. For example, the amount of stocks is limited by the warehouse sizes and distribution capability. However, Farfetch can increase the number of products sold in the online store without physical limitation of stock management. Consequently, Farfetch could deal 300 million Stock Keeping Units (SKUs) for more than 3,200 brands [9].

At a glance, this online platform service is similar to the multi-brand online stores such as Net-A-Porter and Yoox. In modern services in which network externality is a key factor for convenience, scalable online platform service of Farfetch creates new value that is fundamentally different from existing multi-brand online stores. In terms of data source, a large number of products in the service is a reasonable factor in the analysis.

\section{SALES AMOUNT ANALYSIS}

\subsection{Sales amount estimation}

This study investigates brand and product names, regular and selling prices, the number of stocks of luxury fashion products sold in Farfetch. These product attributes are written by HTML files describing web pages of online stores. We try to estimate the sales amount for each product using the product attributes to analyze online luxury market, because we cannot check actual purchases and payment information of online platform service.

This paper denotes selling price and the number of stocks of an item $i$ at time $t$ by $x_{S P, i}(t)$ and $f_{i}(t)$, respectively. The time derivative of the number of stocks $d f_{i}(t) / d t$ expresses the stock changes. If we assume that the sales amount of an item $i$ is calculated by the product of selling price and decrease of the number of stocks, the sales amount $s_{i}(t)$ is written by

$$
s_{i}(t)=\left\{\begin{array}{cc}
0, & \left(\frac{d f_{i}(t)}{d t} \geq 0\right) \\
-x_{S P, i}(t) \frac{d f_{i}(t)}{d t}, & \left(\frac{d f_{i}(t)}{d t}<0\right)
\end{array}\right.
$$

Total sales amount of item $i$ from $t=t_{0}$ to $t=t_{1}$ is expressed as 


$$
S_{i}=\int_{t_{0}}^{t_{1}} s_{i}(t) d t
$$

Since this model does not consider the following issues, there is a possibility that the estimated sales amount may be overabundant.

- Decrease of sales amount by refund, if the return of sold items increases of the number of stocks.

- Decrease of the number of stocks without sales amount.

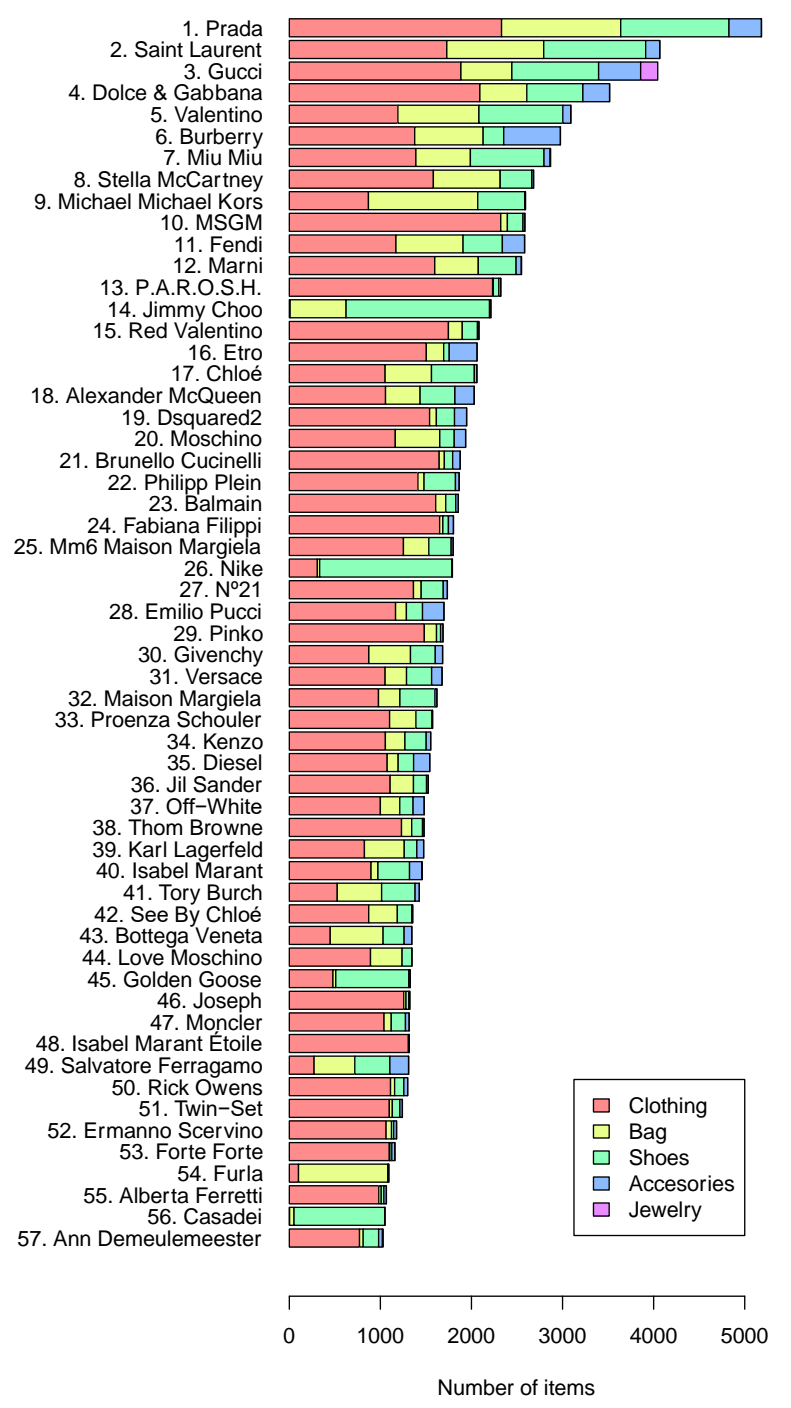

Figure 2: Number of items by brand and by category.

\subsection{Data source}

Female products sold on the platform service Farfetch for the U.S. market had been investigated for 200 days from May 25 to Dec. 19, 2019. The number of unique items was 308,154 and the total number of items was $29,281,286$. These items were sold from 2,513 brands. In general, SKU has been used to manage stocks, in which different sizes and colors of a product are independently counted. Meanwhile, Farfetch counts different sizes of a product as an identical item.

Figure 2 demonstrates the number of investigated items by brand and by product category, where listed 57 brands satisfied that the number of items exceeds 1,000. Prada has sold 5,183 items during the investigated period, which was the largest number of items for a brand. Saint Laurent and Gucci have sold 4,066 and 4,044 items, respectively. Regarding the number of items, rank higher brands mainly account for European luxury fashion brands. Affordable luxury brands such as Michael Michael Kors, Red Valentino, and MM6 Maison Margiela, etc. also appeared in Figure 2. Not only luxury brands but also casual fashion brands MSGM and sport brand Nike appeared as well. Prominent and prestigious luxury brands such as Hermes, Chanel and Dior do not appear, because they limit online distribution channels to their official online stores.

Clothing category accounts for the highest percentage for most of brands as a whole. In terms of rank higher brands in Figure 2, bag, shoes and accessories account for large percentages compared with the other brands. Tory Burch, Bottega Veneta, and Salvatore Ferragaomo show a similar tendency with rank higher brands. Jimmy Choo, Nike, Golden Goose and Casadei show a higher percentage of shoes and Furla show a higher percentage of the bag.

\section{RESULT AND DISCUSSION}

\subsection{Luxury fashion brand}

Figure 3 demonstrates estimated sales amounts by category for the top 50 brands. Estimated sales amount of Gucci during the investigated period is \$US 169,941,100, which is the highest in all brands. Rank higher brands of estimated sales amounts are Prada - \$US 146,681,400, Burberry - \$US 127,731,400, Jimmy Choo - \$US 123,413,100, Dolce \& Gabbana - \$US 93,444,640, Saint Laurent - \$US 78,447,250. Although luxury fashion brands with strong brand equity accounted for the majority of the top 50 brands, casual fashion brands such as Acne Studios, MSGM, DSquared2 also appear in Figure 3. In spite of an emerging brand, Off-White known as a street luxury brand is ranked at 22th place. Jewelry brands, i.e. David Yurman, John Hardly and De Beers are also ranked, in which high unit price of jewelry product raises their estimated sales amounts.

In rank higher brands except shoes specific brand Jimmy Choo, sales amounts of clothing, bag, and shoes are essential to achieve large sales of the brand. This result confirms that category extension in luxury fashion brands [8] is available for making large sales. Percentages of clothing, bag and shoes sales amounts classify the rank higher brands into balanced type brands, e.g. Gucci and 
Prada, and clothing-intensive brands, e.g. Burberry and Dolce \& Gabbana. This classification is closely related to the origin of the luxury brands.

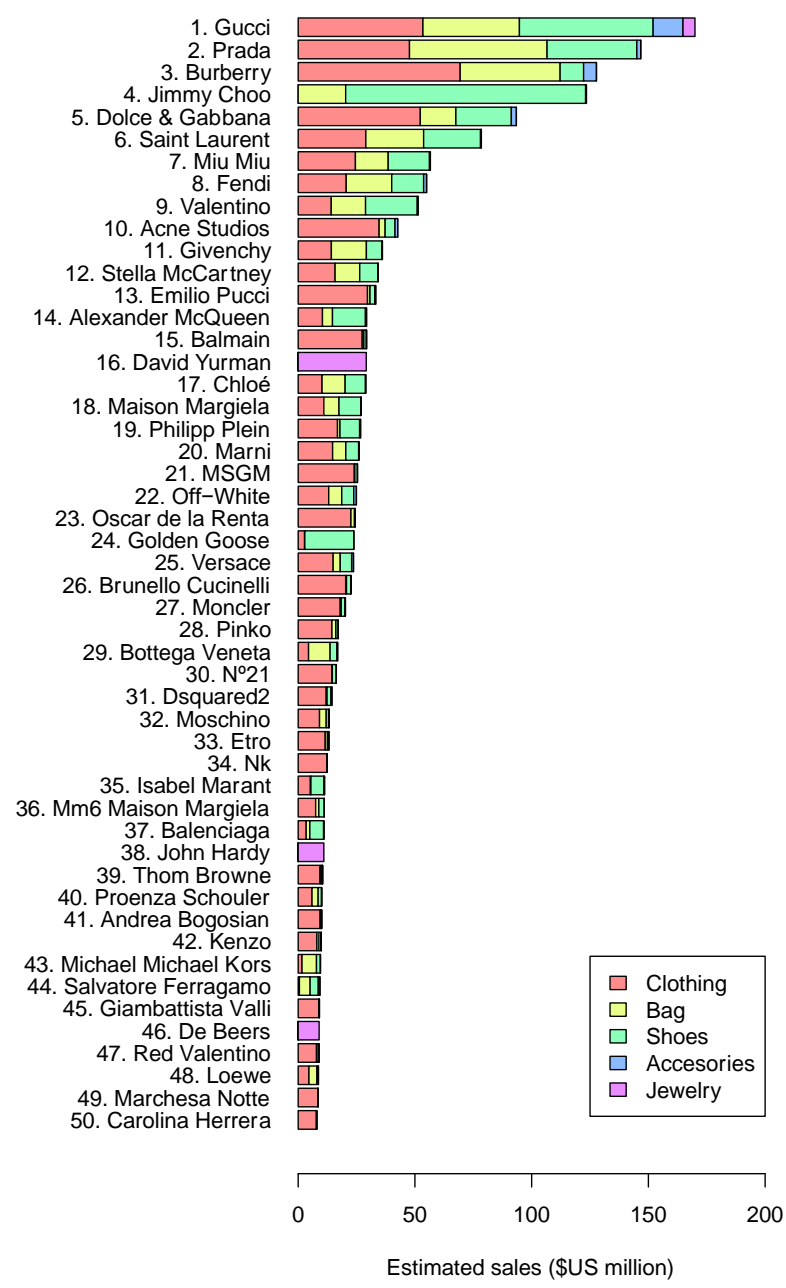

Figure 3: Estimated sales amount by brand and by category.

\subsection{Luxury fashion product}

From high sales amount product attracting a great deal of attention from consumers, we extracted the following product lines (a) Burberry - Heritage trench coats, (b) Gucci - GG Marmont bags, and (c) Prada - Galleria bags. These product lines connote the following factors making brand equity [8]; (i) History and heritage creating reliability to the brands, (ii) Brand identity fascinating consumers, (iii) Product integrity reflecting high quality, creativity and innovative attitudes of the brand, (iv) Design signature symbolizing the brand. In these products, logotypes and ornaments present the brand identity and design signature based on the heritage. Moreover, innovative materials, such as water-proof gabardine of the trench coats and Saffiano leather for bags, retain the product integrity. Consequently, the result suggests that the fascinating products cope with both the heritage and innovation of the luxury fashion brand.

\section{CONCLUSIONS}

This study sheds light on added value created by luxury fashion brands and products, investigated the actual situation of online platform service for luxury fashion products. Firstly, we arranged distribution channels of luxury fashion products, which is closely related to exclusivity, rarity, and extraordinary experiences. The importance of online platform service as a data source is also discussed. Secondly, this paper proposes sales amount analysis and then analyzed 308,154 unique items, to pursue added value of luxury fashion brands and products. The estimated sales amount by brand and by category confirmed availability of category extension in luxury fashion brands. Product integrity of the high sales amount product is also discussed, which attracts a great deal of attention from consumers. This paper could describe the basic methodology of sales amount analysis, though the detailed analysis is not enough. In particular, the integrity of each luxury fashion product will be a significant issue to be discussed in the future.

\section{REFFERENCES}

[1] I. Amed, A. Berg, L. Brandberg, S. Hedrich, J. Leon, R. F. Young; The State of Fashion 2017, The Business of Fashion and McKinsey \& Company, 2016.

[2] J. N Kapferer; Managing luxury brands. Journal of Brand Management, Vol. 4, No. 4, pp. 251-259, 1997.

[3] G. B. Sproles; Analyzing fashion life cyclesPrinciples and perspectives. Journal of Marketing, 45(4), 116-124, 1981.

[4] C. M. Moore and G. Birtwistle; The Burberry business model: creating an international luxury fashion brand. International Journal of Retail \& Distribution Management, Vol. 32, No. 8, pp. 412422, 2004.

[5] K. P. Wiedmann, N. Hennigs and A. Siebels; Valuebased segmentation of luxury consumption behavior. Psychology \& Marketing, Vol. 26, No. 7, pp. 625651, 2009.

[6] K. L. Keller; Conceptualizing, measuring, and managing customer-based brand equity. Journal of marketing, Vol. 57, No. 1, pp. 1-22, 1999.

[7] A. Som and N. Pape; Brand and line extensions: an empirical study from the new age luxury industry. Luxury Research Journal, Vol. 1, No. 1, pp. 18-39, 2015.

[8] A. M. Fionda and C. M. Moore; The anatomy of the luxury fashion brand. Journal of Brand Management, 16(5-6), 347-363, 2009.

[9] E. Jordan; Presentation Details at dbAccess Global Consumer Conference. Retrieved from https://www. farfetchinvestors.com/events-and-presentations /events/ Jan. 30, 2020. 